\title{
Artículo Especial: Obras maestras del arte universal y la medicina: Ulysses de James Joyce (1882 -1941)
}

\author{
Carlos G. Musso *
}

\section{Argumento}

Esta obra relata los acontecimientos acaecidos, a lo largo de un día (el 16 de junio de 1904), en las vidas de Leopold Bloom y Stephen Dedalus, en la ciudad de Dublin. El título de la obra alude al héroe de la Odisea, con la cual guarda un estrecho paralelismo, ya que prácticamente cada capítulo del Ulysses se corresponde a uno de la obra de Homero. Bloom (Ulises) y su mujer, Molly (Penélope), han perdido, 11 años atrás, a su pequeño hijo Rudy, hecho que ha llevado al deterioro de su matrimonio y por ende a la infidelidad, la cual no es más que la máscara tras la cual se oculta el profundo dolor por el hijo fallecido. En este día Bloom comienza a entablar una relación paternal con el joven Stephen (Telémaco) a través de la cual siente redimir su dolor de padre. Si bien esta obra está plagada de simbologías, aquí solo nos referiremos a aquella que explora la verdadera dimensión de la organicidad.

\section{Ulysses y la meta-anatomía humana}

Joyce dedica cada capítulo de esta obra a un órgano del cuerpo, una forma del arte, un color y una técnica narrativa, aunque el estilo que predomina es el del monólogo interior o representación del flujo del pensamiento. A través de este juego de correspondencias, el autor expresa el concepto de que cada víscera del cuerpo humano se prolonga más allá de su anatomía convencional en un haz de representaciones que de ella posee la mente (plano neurológico), la psiquis (plano psicológico) y la cultura (plano social). Vale decir, que así como cada víscera se prolonga, en un plano infra-visceral, en una diversidad de tejidos, células y organelas, cada órgano, desde un plano supra-visceral, se prolonga en una diversidad de re- presentaciones neuro-psico-sociales. Es así, por ejemplo, que el músculo cardíaco se prolonga más allá de su pericardio en sus representaciones neurológicas (centro cardíaco bulbar, componentes cardíacos del sistema nervioso autónomo, etc.), psíquicas (registros límbicos de lo cardíaco) y simbólicas (la palabra "corazón" y sus diversas asociaciones lingüístico-culturales con lo central, el coraje y el afecto). Resulta entonces que tanto los procesos normales como patológicos pueden fluir a través de este continuo en uno u otro sentido, de modo que fenómenos originados en el plano celular pueden justificar la aparición de fenómenos desarrollados en el plano social y viceversa, siendo el lenguaje el hilo conector que hilvana los sucesivos planos que van desde el órgano somático (la mano anatómica), su representación neuroanatómica (la mano del homúnculo cerebral sensitivo y motor), su representación psíquica (la mano límbica) hasta su representación simbólica (la categoría mano en el discurso y la cultura), y desde donde este meta-órgano (lo manual) entra en conexión, a través de la red lingüística, con el resto de los meta-órganos propios y ajenos, de igual forma que los órganos somáticos se vinculan con los otros de la economía a través del sistema nervioso, endócrino e inmune; de ahí que la enfermedad de un órgano no sólo sea la enfermedad de sus células (Virchow), sino también la de sus representaciones mentales, psíquicas y simbólicas (Weizaecker-Chiozza), pues todo proceso fisiológico o patológico se desarrolla, en algún grado, simultáneamente en todos estos planos cuya naturaleza diversa es ficticia, pues en realidad proviene de nuestra falta de sutiliza a la hora de percibir los fenómenos vitales. Concluimos que el Ulysses de Joyce nos ayuda a comprender que existe un continuo desde el plano molecular hasta el plano social a lo largo del cual la organicidad vive, se expresa, enferma y sana.

Bibliografía recomendada

Joyce J. Ulises. Buenos Aires. Losada. 1999

Strick J. Ulysses. 1967 (film)

Gamerro C. Ulises. Claves de lectura. Buenos Aires. Norma: 2008

Musso C. Obras maestras del arte universal y la medicina: "El malentendido" de Albert Camus (1913-1960). Evidencia.2008; 11 (2): 48

Chiozza L. Corazón, hígado y cerebro. Buenos Aires. Zorzal. 2009

Musso CG, Enz P. Corazón, hombre y cultura. Revista del Hospital Italiano de Buenos Aires. 2010; 30(2): 1-3

Chiozza L. Hipertensión. ¿soy, o estoy, hipertenso? Buenos Aires. Zorzal. 2011

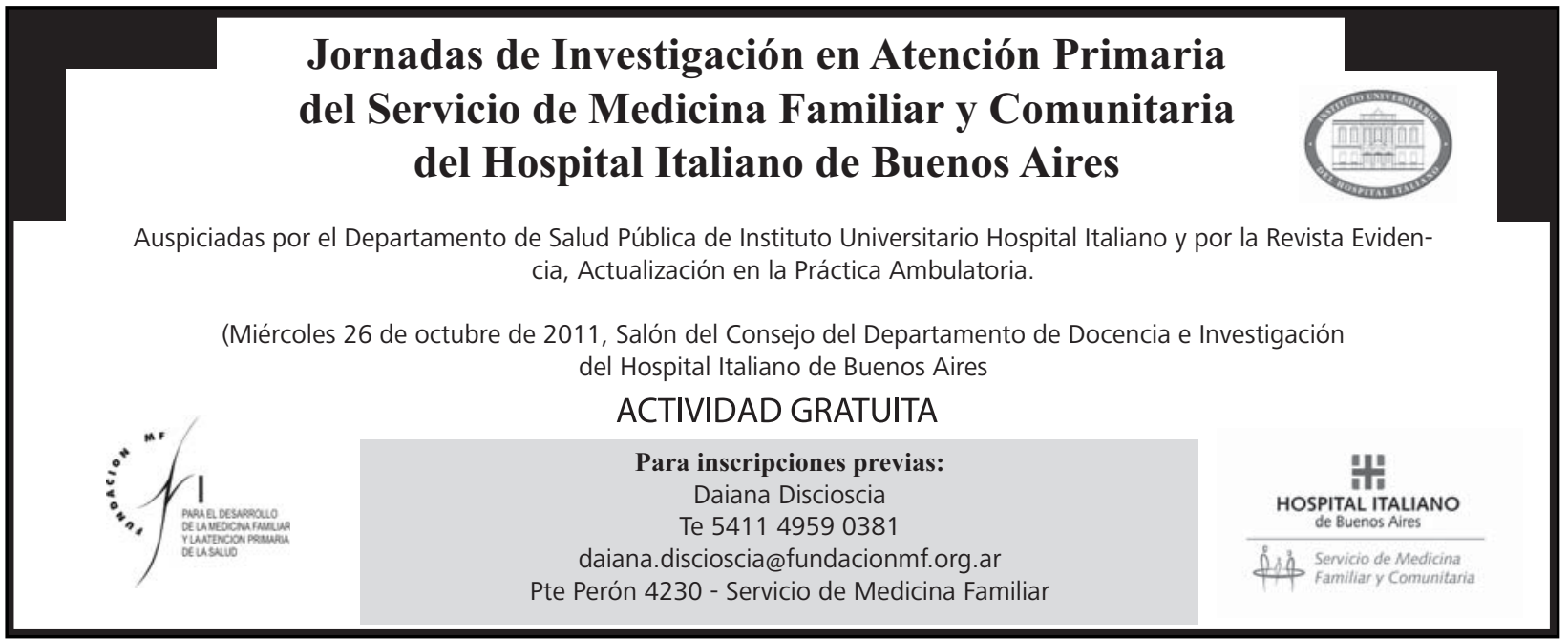

* Servicio de Nefrología del Hospital Italiano de Buenos Aires carlos.musso@ hospitalitaliano.org.ar 